\title{
Effect of a condenser on the analysis by dynamic headspace-GC-MS of the volatile fraction of a cheese
}

\author{
D. Canac-Arteaga, C. Viallon, J.-L. Berdagué* \\ Laboratoire Flaveur, Station de Recherches sur la Viande, INRA de Theix, 63122 Ceyrat, France
}

\begin{abstract}
The insertion of a condenser in the dynamic headspace - GC-MS analysis circuit allows part of the water contained in a water-rich sample to be condensed. The impact of such a condenser on the chromatographic profiles of a cheese was studied for temperatures ranging from -12 to $0{ }^{\circ} \mathrm{C}$. The condenser collected the water, but also some of the volatile components of the cheese, irrespective of its operating temperature. Insertion of a condenser improved the overall quality of the chromatographic signal, but caused major changes in the chromatographic profile of the cheese.
\end{abstract}

Keywords. Volatile compounds - cheese - condenser - purge-and-trap - GC-MS

\section{Introduction}

The combination of dynamic headspace analysis, gas phase chromatography and mass spectrometry (DHS-GC-MS) is classically used to characterize the volatile fraction of food products [1-7]. Dynamic headspace analysis consists in stripping the volatile components of a sample with a carrier gas and then trapping them on an adsorbent. However, water, often the main volatile component of foodstuffs, generates artifacts in the successive steps of the analysis, such as blocking of cryofocusing [8,9], shift of retention time [10], destruction of the stationary phase of the column [11], and diminution of the abundance of the volatile compounds [12].

To eliminate the water during the analysis of water-rich products, several methods using condensers have been tested or marketed. These are all based on condensers working at ranging temperatures, and installed either upstream (Rosen \& Pankow, 1991; Wang et al., 1983; Chrompack, 1989; O.I. Analytical, 1992; CDS Analytical Inc., 1994) [12-16] or downstream of the adsorbent (Tekmar, 1994) [17]. These water traps are often efficient for the analysis of the apolar volatile fraction of water-rich products. However, very few studies (Noij et al., 1987) [8] have clearly described the artifacts they generate during the analysis of water-rich products comprising polar and apolar volatile fractions, like most foodstuffs.

The aim of the present study was to describe the analytical consequences of using a glass condenser located between the sample being analysed (a cheese) and the Tenax adsorbent in DHS-GC-MS. This trap operated at six temperatures between 0 and $-12{ }^{\circ} \mathrm{C}$. The instrumentation used was specially built to analyse, in two successive steps, (i) the volatile fraction not retained by the condenser but adsorbed on the Tenax trap (which is classical), and then (ii) the volatile fraction retained by the condenser. The chromatographic profiles of both volatile fractions were compared with the reference profile of the same cheese obtained with no condenser.

\section{Materials and methods}

\section{Sample material}

Commercial wax-coated pre-portioned hard processed cheeses were selected (mini-Babybel). This product is biochemically stable, homogeneous and has a relatively simple volatile fraction. Its water content is $48 \%$ and its water activity is 0.97 .

\section{Storage of samples}

The cheeses in their wax packaging were wrapped in aluminium foil, vacuum-sealed in a polyethylene bag and stored at $-25^{\circ} \mathrm{C}$. Before each analysis, the sample was left overnight at room temperature.

\section{Purge-and-trap of volatile components}

The volatile fraction of the cheese was analysed using a Tekmar LSC 2000 Purge-and-Trap instrument (Cincinnati, $\mathrm{OH} 45234$, USA). Samples of $4 \mathrm{~g}$ of cheese cut into cubes of about $3 \mathrm{~mm}$ side were placed on glass wool (reference Prolabo $\mathrm{n}^{\circ} 23039.293$ ) at the bottom of a glass extraction cell (height: $70 \mathrm{~mm}$, external diameter: $34 \mathrm{~mm}$ ). The extraction cell was swept with a purge gas helium (purity $=99.995 \%$, Air Liquide) at a flow rate of $60 \mathrm{ml} \cdot \mathrm{min}^{-1}$ (steps 1 or 1 ' in figure 1 ). The extractions were

* Correspondence and reprints.

Received June 18, 1999; revised November 30, 1999; accepted December 17, 1999. 


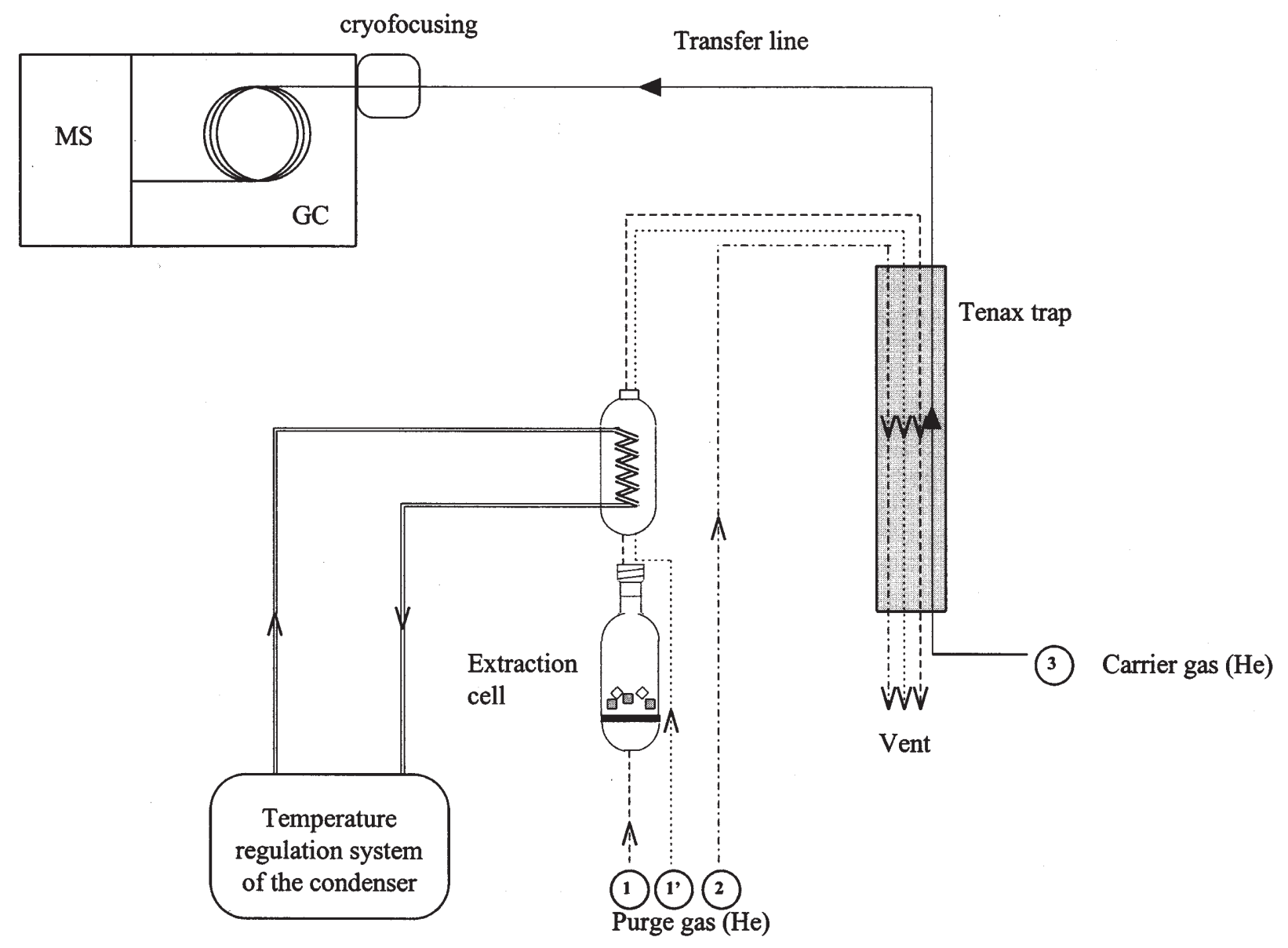

Fig. 1. Schematic diagram of the circuit for the analysis of volatile compounds by purge-and-trap coupled with gas chromatography-mass spectrometry.

(1) Purge of the volatile compounds with the condenser in cold mode and trapping on Tenax

(1) Purge of the volatile compounds with the condenser in warm mode and trapping on Tenax

(2) Dry purge

(3) Desorption of the volatile compounds trapped on the Tenax, cryofocusing at $-150{ }^{\circ} \mathrm{C}$ and injection by heating in the capillary column.

carried out at $19^{\circ} \mathrm{C}$ for 20 min with or without a condenser located between the extraction cell and the adsorbent. The adsorbent used was Tenax 60/80 mesh, length $24 \mathrm{~cm}$, internal diameter $1 / 8$ inch (reference Supelco $\mathrm{n}^{\circ} 2-1059-\mathrm{U}$ ), operating temperature $30{ }^{\circ} \mathrm{C}$.

\section{Operation of condenser}

The condenser was designed to retain, by condensation or freezing, some of the water desorbed from the cheese. It comprised a glass cylinder (height: $80 \mathrm{~mm}$, external diameter: $34 \mathrm{~mm}$ ) with a coiled glass tube running through it (internal diameter: $6 \mathrm{~mm}$, four turns in $40 \mathrm{~mm}$ ), in which flowed a heat-exchange fluid (glyceol RX, Renault), the temperature of which could be set at $-15^{\circ} \mathrm{C}$ to $60{ }^{\circ} \mathrm{C}$. To study the impact of the condenser and its operating temperature on the results of the analysis of the cheese volatile components, six experiments were repeated twice at tem- peratures of $0,-1,-5,-7,-10$ and $-12{ }^{\circ} \mathrm{C}$. Each experiment comprised two discontinuous phases for the analysis of:

(i) the volatile components desorbed by the cheese but not retained by the condenser. This phase 1 comprised steps 1,2 and 3 shown in figure 1, and is designated NRC (for Non-Retained on Condenser), and

(ii) the volatile components retained with the water on the condenser. This phase 2 comprised steps 1', 2 and 3 shown in figure 1 and is designated RC (for Retained on Condenser). To analyse the RC phase, the extraction cell containing the cheese sample was disconnected from the helium extraction circuit and the condenser heated to $60{ }^{\circ} \mathrm{C}$ for $6 \mathrm{~min}$ before stripping the volatile components from the condenser to the Tenax trap using helium (purity $=99.995 \%$, Air Liquide) at a flow rate of 60 ml.min ${ }^{-1}$ for $20 \mathrm{~min}$. 


\section{Elimination of the water retained on the adsorbent using the dry purge method}

This operation (step 2 in figure 1) eliminates, by drying with helium, some of the water retained on the Tenax during the trapping of the volatile components. After preliminary trials carried out with and without the dry purge, with a condenser operating at $-12,-7$ and $0{ }^{\circ} \mathrm{C}$, the duration of this operation was set at $10 \mathrm{~min}$ for all the analyses. This value, which is slightly higher than that recommended by Canac-Arteaga et al. [18] affords an essentially artifact-free analysis of the very water-rich volatile fraction retained by the condenser.

\section{Injection of volatile components into the capillary column}

The volatile components were desorbed from the Tenax at $180{ }^{\circ} \mathrm{C}$ for $5 \mathrm{~min}$ using helium (purity $=99.9995 \%$, Air Liquide) as carrier gas with a flow rate of $1.4 \mathrm{ml} . \mathrm{min}^{-1}$, injected in a transfer line (deactivated fused silica precolumn, internal diameter: $0.53 \mathrm{~mm}$, length: $1.5 \mathrm{~m}$, Varian). They were then cryofocused at $-150{ }^{\circ} \mathrm{C}$ in a $3-\mathrm{cm}$ segment of the precolumn using a liquid nitrogen cooling system (step 3 in figure 1). Injection into the chromatography column was then carried out by heating the precolumn for $2 \mathrm{~min}$ at $225^{\circ} \mathrm{C}$. To eliminate any potential memory effects between successive analyses, the Tenax trap was then heated for $20 \mathrm{~min}$ at $180{ }^{\circ} \mathrm{C}$.

\section{Separation, detection and identification of the volatile components}

The volatile components were separated with a capillary column (SPB5, film thickness: $1 \mu \mathrm{m}, 60 \mathrm{~m} \times 0.32 \mathrm{~mm}$; Supelco). The oven temperature of the chromatograph (Hewlett Packard 5890) was programmed as follows: 5 min isotherm at $33{ }^{\circ} \mathrm{C}$, heated at $3{ }^{\circ} \mathrm{C} \cdot \mathrm{min}^{-1}$ up to $200{ }^{\circ} \mathrm{C}$, then $2 \mathrm{~min}$ hold at $200{ }^{\circ} \mathrm{C}$. The volatile components were detected by mass spectrometry with electron impact at $70 \mathrm{eV}$ (Hewlett Packard 5971S). Data acquisition was set at 3 scan. $\mathrm{s}^{-1}$ applied over the ion mass range 15 to 190 daltons. The volatile components were identified by comparing their spectra with those of the NBS 75K database (1994) and their retention indices with those of the database compiled by Kondjoyan and Berdagué (1996) [19].

\section{Baseline and calculation of peak area}

The baseline level (expressed in arbitrary abundance units) was measured between 40 and $45 \mathrm{~min}$ in a peak-free segment. To determine the origin of the noise in this chromatogram segment, an average spectrum was recorded. The origin of this noise has already been described by CanacArteaga et al. [18]. The peak area of the volatile components (arbitrary units of area, a.u.a.) was integrated from specific ions for each of the molecules (for example: $\mathrm{m} / \mathrm{z}=18$ for water) to circumvent coelution problems. The integrations were performed with MSD ChemStation software from Hewlett Packard. The integration parameters were as follows: initial detection threshold: 8 a.u.a.; initial peak width: $0.2 \mathrm{~min}$; minimum peak area: 10,000 a.u.a.

\section{Statistical analyses}

For each volatile component, a comparison for all temperatures of the fractions retained by the condenser (RC) and those not retained (NRC) was made with a reference analysis, i.e., with no condenser and with a dry purge under the conditions described by Canac-Arteaga et al. [18]. As in all the tests performed in this work, the reference analysis was carried out twice. To draw up a balance of transfer of volatile components in the different phases of the tests with the condenser, the sum of the retained (RC) and non-retained (NRC) volatile components was also calculated. To make these different comparisons, average values and minima and maxima of the distributions are presented in bar charts. The effect of temperature on each of the peaks of the volatile fractions either retained by the condenser (RC) or nonretained by the condenser (NRC) was studied for each of the fractions by an analysis of variance of the type: $\mathrm{X}_{i, j}=\mu+\mathrm{T}_{i}+\varepsilon_{j}$ (with $\mathrm{X}_{i, j}=$ area of each of the chromatogram peaks, $\mathrm{T}_{i}=$ effect of the condenser temperature, $\varepsilon_{j}=$ residual variations, $i=6$ temperatures and $j=2$ repeats).

\section{Results - Discussion}

In order to describe the capacity of the condenser to retain water during the NRC and RC phases of the analyses, preliminary tests were conducted without dry purge of the Tenax trap at temperatures of $-12,-7$ and $0{ }^{\circ} \mathrm{C}$. These preliminary tests showed that the condenser retained a large proportion of the water desorbed from the cheese sample (Fig. 2, RC phase of the analyses). Its best water retaining performance was observed at $-7{ }^{\circ} \mathrm{C}$ and $-12{ }^{\circ} \mathrm{C}$. However, a fraction of the water desorbed from the cheese was not

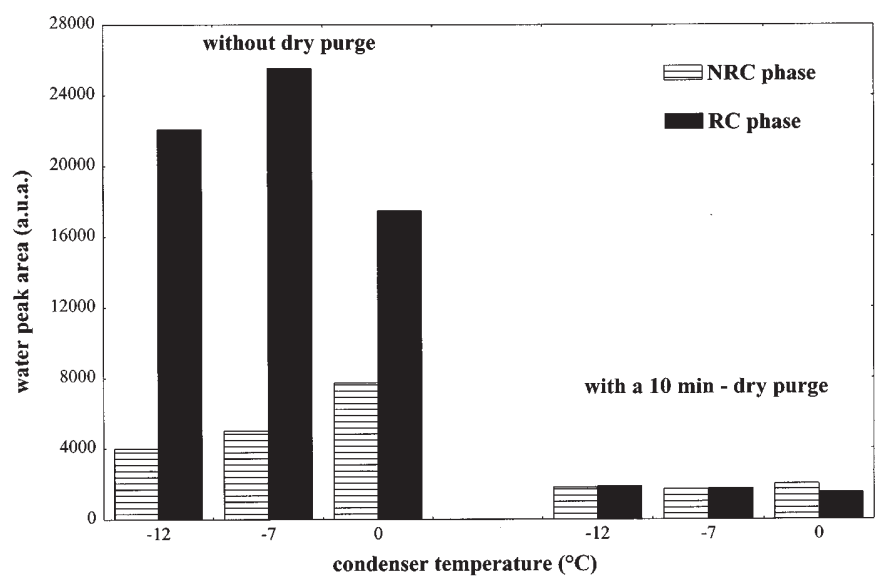

Fig. 2. Water peak area versus condenser temperature $(0,-7$, $-12{ }^{\circ} \mathrm{C}$ ) and obtained without dry purge (A) and with a dry purge of $10 \mathrm{~min}(\mathrm{~B})$. 
retained by the condenser, whatever the temperature set. This water was found in non-negligible amounts in the Tenax trap during the NRC phase (Fig. 2).

The effect of a ten-minute dry purge of the Tenax trap masked that one of the condenser on the water peak area in both analysis phases (Fig. 2). This observation confirms both the efficiency of the dry purge for rapidly removing the water adsorbed on the Tenax, and the existence of residual water difficult to eliminate from the adsorbent (CanacArteaga et al.) [18].

With no dry purge, injection of excess water into the capillary column prevents analysis of the volatile components retained with the water on the condenser (RC phase). In these conditions, the tailing of the water peak from 4 to 50 min makes the chromatograms impossible to interpret: split and highly asymmetrical peaks for most polar components (e.g., ethanol, 3-hydroxy-2-butanone, 2-butanone...), negative shift of more than one minute of all the chromatogram peaks, and marked bleeding of stationary phase. Accordingly, for the subsequent experiments, a $10 \mathrm{~min}$ dry purge was systematically included in the analyse procedure to make artifact-free comparisons between NRC and RC phases, and the reference analyses.

Comparison of the cheese chromatogram obtained with no condenser (see a reference analysis, figure $3 \mathrm{~A}$ ) with those obtained in the NRC and RC phases using the condenser at $-7{ }^{\circ} \mathrm{C}$ (Fig. 3B and 3C) shows major differences. Qualitatively, almost all the volatile components identified in the total fraction used as reference also appear in the NRC and RC phases with the condenser. Only acetic acid present in the control sample was not found in either NRC or RC phases. However, according to the component, the quantities chromatographed in NRC and RC phases varied widely. Certain compounds such as ethanol, acetone, dimethylsulfide, 2-butanone, ethyl acetate, 3-methyl butanal, 2-pentanone, propyl acetate, dimethyl disulfide, toluene, hexanal, octane and alpha-pinene were more abundant during the NRC phase (Fig. 3B and Fig. 4). Consequently they were weakly retained by the condenser, but strongly retained on the Tenax trap. Conversely, other compounds such as 2,3butanedione, 3-hydroxy-2-butanone, 2-heptanone, 6-methyl5-hepten-2-one, octanal, and nonanal were more abundant during the RC phase (Fig. 3C and Fig. 4). These components were retained in the condenser during the NRC phase, and then retained on the Tenax trap during the RC phase. Analysis of variance showed that the distribution of all the volatile components between the NRC and RC phases was not significantly different, whatever the condenser temperature.

The interpretation of these results is difficult, because the distribution of the volatile components between NRC and RC phases with the condenser seems not solely due to their polarity, i.e., their solubility in water. For toluene and 3hydroxy-2-butanone the polarity rule was followed, toluene (apolar compound) being more abundant in the NRC phase and 3-hydroxy-2-butanone (highly polar compound) being more abundant in the $\mathrm{RC}$ phase (Fig. 3B and 3C). In contrast, for acetone and 3-hydroxy-2-butanone (both very polar compounds), the polarity rule was not followed, acetone being detected in larger amounts in the NRC phase, while almost all the 3-hydroxy-2-butanone was found in the RC phase. Therefore, mechanisms involving the volatility of the compounds also have to be considered. Noij et al. [8] found that polar compounds or compounds with boiling points close to that of water were retained with water in a condenser at $-15^{\circ} \mathrm{C}$, using a purge and condenser capillary gas chromatography of the volatile fraction of aqueous mixtures.

During the NRC phase of the analysis, the abundance of volatile components was most often less than that measured during the reference analysis, which means that introducing a condenser causes losses. Theoretically, the sum of the areas of the NRC phase and RC phase chromatograms should equal the mean area of the reference chromatogram (with no condenser). In fact, the area obtained is only $86 \%$ of that of the reference chromatogram. Figure 4 shows that for most of the components the sum of areas obtained in the $\mathrm{NRC}$ and RC phases of the analysis is less than the area obtained in the reference analyses. This area discrepancy arises because a fraction of the volatile components retained by the condenser in NRC phase flows unadsorbed through the Tenax during the RC phase. This lack of adsorption of volatile compounds on the Tenax during the RC phase can be explained by the large amounts of water evaporated during the reheating of the condenser, which induces azeotropic equilibria (interactions between water and volatile compounds) and mechanisms of competition between water, volatile compounds and adsorbent, that are liable to reduce the efficiency of the adsorbent. The components lost with the water in this way include all the acetic acid, much of the ethanol, 2,3-butanedione, 3-hydroxy-2-butanone and 2heptanone.

Comparison of the three chromatograms (Fig. 3) shows that the three main cheese peaks (2,3-butanedione, 2butanone and 3-hydroxy-2-butanone) perturb the return of the signal to its baseline. Because of the simultaneous injection of a large quantity of water and volatile compounds into the separation column, the noise measured during the reference analysis and the RC phase with the condenser was always high.

\section{Conclusion}

The specific instrumentation used to study the effect of a condenser on the analysis of the dynamic headspace of a cheese by GC-MS afforded separate analysis of:

- the volatile fraction not retained by the condenser but adsorbed by the Tenax trap, and

- the volatile fraction retained by the condenser and adsorbed by the Tenax trap.

The experiments carried out showed that the use of a condenser located between the sample and the Tenax adsorbent: 


\section{Original articles}
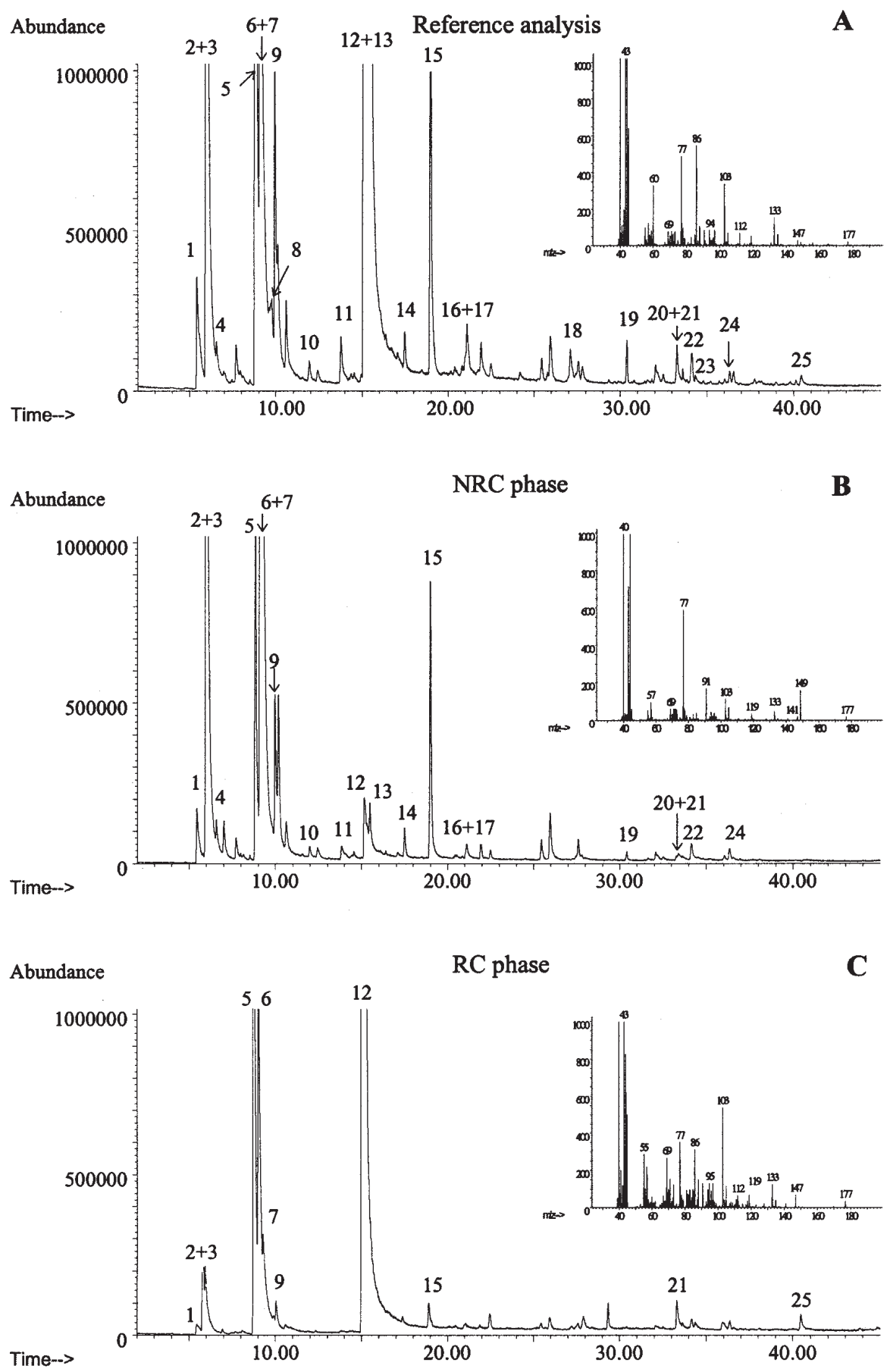

Fig. 3.

A: Chromatographic profile of the reference sample obtained by dynamic headspace - GC-MS without the condenser and with a dry purge of $10 \mathrm{~min}(\mathrm{~m} / \mathrm{z} 33-190)$.

B: Chromatographic profile of the volatile fraction of the cheese obtained during the NRC phase of the analysis with the condenser at $-7^{\circ} \mathrm{C}$ and with a dry purge of $10 \mathrm{~min}(\mathrm{~m} / \mathrm{z} 33-190)$.

C: Chromatographic profile of the volatile compounds retained on the condenser: $\mathrm{RC}$ phase of the analysis with the condenser at $60{ }^{\circ} \mathrm{C}$ and with a dry purge of $10 \mathrm{~min}(\mathrm{~m} / \mathrm{z} 33-190)$.

The compounds identified were in order of elution: $1=$ ethanol, $2=$ acetone, $3=2$-propanol, $4=$ dimethyl sulfide, $5=2,3$-butanedione, 6 - 2-butanone, $7=2$-butanol, $8=$ acetic acid, $9=$ ethylacetate, $10=3$-methyl-butanal, $11=2$-pentanone, $12=3$-hydroxy-2-butanone, $13=$ propylacetate, $14=$ dimethyl disulfide, $15=$ toluene, $16=$ hexanal, $17=$ octane, $18=2$-heptanone, $19=$ alpha pinene, $20=$ beta pinene, 21 = 6-methyl-5-hepten-2-one, 22 = decane, 23 = octanal, 24 = limonene, 25 = nonanal.

For each chromatographic profile, the abundance of ions in the baseline noise is presented. 

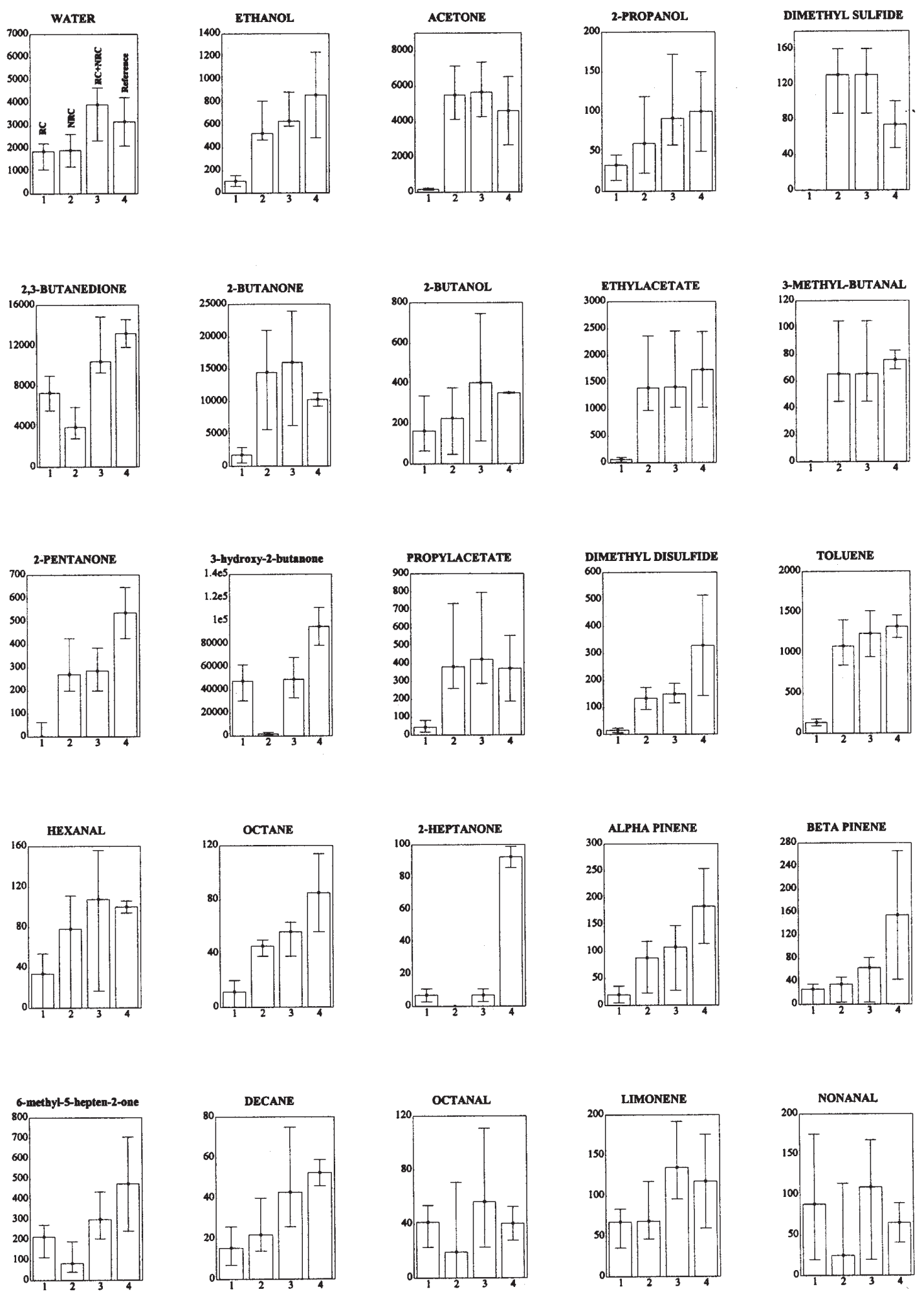

Fig. 4. Bar charts representing average, minima and maxima values of each volatile component area (a.u.a.) for:

1. The fraction retained by the condenser ( $\mathrm{RC}$ phase)

2. The fraction not retained by the condenser but retained by the Tenax (NRC phase)

3. The sum of the fractions retained and not retained by the condenser during the RC and NRC phases

4. The fraction obtained during the reference analysis.

The volatile components are arranged from left to right in increasing order of Kovats indices. 


\section{Original articles}

- perturbs the analytical results both qualitatively and quantitatively, irrespective of its operating temperature (some polar components may not even appear in the chromatogram when a condenser is used), and

- reduces the artifacts due to the injection of large amounts of water into the capillary column, and thereby improves the chromatographic quality.

In conclusion, the use of a condenser cannot be recommended for the complete analysis of the volatile fractions of foodstuffs.

\section{References}

1. Bosset, J. O.; Gauch, R. Int. Dairy Journal 1993, 3, 359-377.

2. Christensen, T. C.; Hølmer, G. Milchwissenschaft 1996, 51, 134-138.

3. Heikes, D. L.; Jensen, S. R.; Fleming-Jones, M. E. J. Agric. Food Chem. 1995, 43, 2869-2875.

4. Malundo, T. M. M.; Baldwin, E. A.; Moshonas, M. G.; Baker, R. A.; Shewfelt, R. L. J. Agric. Food Chem. 1997, 45, 21872194.

5. Mateo, J.; Zumalacarregui, J. M. Meat Sci. 1996, 44, 255-273.

6. Narain, N.; Hsieh, T. C.-Y.; Johnson, C. E. J. Food Sci. 1990, $55,1303-1307$.
7. Ott, A.; Fay, L. B.; Chaintreau, A. J. Agric. Food Chem. 1997, 45, 850-858.

8. Noij, T.; Van Es, A.; Cramers, C.; Rijks, J. J. High Resolution Chromat. \& Chromat. Communic. 1987, 10, 60-66.

9. Shimoda, M.; Shibamoto, T. J. High Resol. Chromatogr. 1990, 13, 518-520.

10. Chen, G.-C.; Rohwer, E.R. J. Chromatogr. A 1999, 845, 4352.

11. Kostiainen, R. Chromatographia 1994, 38, 709-714.

12. Rosen, M. E.; Pankow, J. F. J. Chromatogr. 1991, 537, 321328.

13. Wang, T.H.; Shanfield, H.; Zlatkis, A. Chromatographia 1983, 17, 411-417.

14. Purge and trap injector CP4010, 1989, Chrompack, The Netherlands.

15. O.I. Analytical Technical report No. 04201092, 1992; O.I. Analytical, U.S.A.

16. CDS 6000, 1994, CDS Analytical Inc., Oxford, U.S.A.

17. Tekmar 3000 purge and trap concentrator, 1994, TekmarDohrmann, Cincinnati, U.S.A.

18. Canac-Arteaga, D.; Viallon, C.; Berdagué, J.-L. Analusis, in press.

19. Kondjoyan, N.; Berdagué, J.-L. A compilation of relative retention indices for the analysis of aromatic compounds; Clermont-Ferrand: Laboratoire Flaveur, 1996. 